\title{
PEMBANGUNAN TAMAN LINGKUNGAN PERUMAHAN VILLA BOGOR INDAH, KOTA BOGOR
}

\author{
Rahmat Rejoni $^{1}$, Andrianto Kusumoarto ${ }^{2}$, Agus Gunawan ${ }^{3}$, dan Devi Libriati ${ }^{4}$ \\ ${ }^{1}$ Dosen Program Studi Arsitektur, Fakultas Teknik dan Ilmu Komputer, Universitas Indraprasta PGRI, Jakarta \\ rahmat.rejoni@unindra.ac.id \\ ${ }^{2}$ Dosen Program Studi Arsitektur, Fakultas Teknik dan Ilmu Komputer, Universitas Indraprasta PGRI, Jakarta \\ andrianto.kusumoarto@unindra.ac.id \\ ${ }^{3}$ Bidang Pertamanan, PJU, dan Dekorasi Kota, Dinas Perumahan dan Permukiman, Pemerintah Kota Bogor \\ ${ }^{4}$ Bidang Pertamanan, PJU, dan Dekorasi Kota, Dinas Perumahan dan Permukiman, Pemerintah Kota Bogor
}

\begin{abstract}
The environmental park in Bogor Indah Villa Housing is one of the green open spaces in the middle of the settlement that functions as a park with urban agricultural activities, recreation, and a collection of plants (arboretum). The purpose of this activity is to design and build an environmental park in the Villa Bogor Indah housing based on community participation. The method used is descriptive qualitative method with a community-based design approach. The design of environmental parks is an activity-based design of the perceptions, desires and behaviors of the community of residents of the environment. The area of this environmental park is 1,680,749 m2. Residents of settlements want an environmental park that can function as an urban farming facility of 55\%, as a collection of plants of $40 \%$ and as a passive recreation facility of 5\%. Functions that can be developed in the environment of Villa Bogor Indah Housing, namely: 1) urban farming; 2) collection of plants; 3) passive recreation; and 4) parking. The people's desire for urban farming activities provides a good nuance towards the design of environmental parks as a space for activities with residents. Public awareness of the environment is also manifested by the desire for the presence of environmental parks as a space for the collection of plants (arboretum), especially rare plants.
\end{abstract}

KeyWords: arboretum, community based design, landscape planning and design, park environment, urban farming, urban green open space

Abstrak : Taman lingkungan di Perumahan Villa Bogor Indah merupakan salah satu ruang
terbuka hijau di tengah permukiman yang berfungsi sebagai taman dengan aktivitas
pertanian perkotaan, rekreasi, dan koleksi tanaman (arboretum). Tujuan dari kegiatan ini
adalah membuat desain dan melakukan pembangunan taman lingkungan di Perumahan
Villa Bogor Indah berbasis partisipasi masyarakat. Metode yang digunakan adalah
metode deskriptif kualitatif dengan pendekatan desain berbasis komunitas. Desain taman
lingkungan yang dilakukan adalah desain berbasis aktivitas persepsi, keinginan dan
prilaku komunitas penghuni lingkungan tersebut. Luas taman lingkungan ini adalah
1.680,749 m². Penghuni permukiman menginginkan taman lingkungan dapat berfungsi
sebagai sarana urban farming $55 \%$, sebagai koleksi tanaman $40 \%$ dan sebagai sarana
rekreasi pasif $5 \%$. Fungsi yang dapat dikembangkan di taman lingkungan Perumahan
Villa Bogor Indah, yakni : 1) urban farming; 2) koleksi tanaman; 3) rekreasi pasif; dan 4 )
parkir. Keinginan masyarakat terhadap adanya aktivitas urban farming memberikan
nuansa yang baik terhadap desain taman lingkungan sebagai ruang aktivitas bersama
warga. Kesadaran masyarakat terhadap lingkungannya diwujudkan juga dengan
keinginan hadirnya taman lingkungan sebagai ruang untuk koleksi tanaman (arboretum)
terutama tanaman langka. Kata Kunci : Arboretum, Desain Berbasis Komunitas, Perencanaan dan Desain Lanskap, Ruang Terbuka Hijau Kawasan Perkotaan, Taman Lingkungan, Urban Farming

\section{PENDAHULUAN}

Ruang Terbuka Hijau Kawasan Perkotaan (RTHKP) adalah ruang yang termasuk ke dalam fasilitas sosial dan umum, salah satunya berbentuk taman baik taman kota maupun taman lingkungan (Permen PU, 2008). Keberadaan taman-taman ini menjadi salah satu komponen 
RTHKP yang potensial dikembangkan di Kota Bogor, menjadi salah satu prioritas dalam pengembangan kota di Kota Bogor. Pembangunan RTH juga dapat mempengaruhi kenyamanan iklim mikro di sekitar tapak (Hashem Akbari, Davis, Dorsano, Huang, \& Winnet, 1992; DOE, 1993).

Taman lingkungan adalah lahan terbuka yang berfungsi sosial dan estetik sebagai sarana kegiatan rekreatif, edukasi atau kegiatan lain pada tingkat lingkungan (Permen PU, 2008). Taman lingkungan dapat pula diartikan unit dasar (terkecil) dari sistem taman yang ditujukan untuk rekreasi dan fungsi sosial dan difokuskan pada rekreasi informal (APA, 2007). Keberadaan taman lingkungan memiliki potensi untuk memberikan nilai manfaat yang sangat penting bagi masyarakat permukiman untuk beraktivitas bersama di ruang luar, selain itu juga memberikan nilai estetika lingkungan yang dapat dirasakan oleh penghuni permukiman.

Salah satu taman lingkungan di Kota Bogor adalah taman lingkungan Perumahan Villa Bogor Indah. Saat ini kondisinya kurang terkelola dengan baik, banyak rumput liar dan tanaman yang berada di lokasi kurang terawat (Gambar 1).

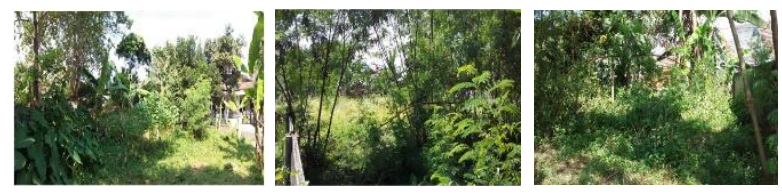

Gambar 1. Kondisi lahan untuk taman lingkungan di Perumahan Villa Bogor Indah

Masyarakat menginginkan ada upaya yang harus segera dilakukan adalah memfungsikan kembali sebagai RTHKP dalam bentuk arboretum (koleksi tanaman) dan taman lingkungan yang berfungsi selain sebagai tanaman obat juga berfungsi sebagai sayuran dan buah serta kegunaan lainnya serta ramah lingkungan dan estetik. RTHKP di lingkungan tersebut dapat berfungsi sebagai wahana interaksi sosial masyarakat dan lokasi bercocok tanaman sayuran, tanaman buah, tanaman obat, dan palawija. Untuk mengoptimalkan fungsi dan aktivitas taman lingkungan dan hutan kota tersebut perlu dilakukan desain taman lingkungan berbasis komunitas. Perencanaan yang dilakukan mampu mengurangi dampak kerusakan lingkungan secara berangsur-angsur (Sidle, Gallina, dan Gomi, 2017). Modal sosial harus dipertimbangkan sehingga dapat memberikan kepuasan dan keberlanjutan komunitas (Kwon, Lee, dan Xiao, 2017).

Taman merupakan salah satu bentuk aset pemerintah daerah. Siregar (2004: 58) menjelaskan aset melalui perspektif pembangunan berkelanjutan didasarkan pada tiga aspek pokok, yaitu sumber daya alam, sumber daya manusia, dan infrastruktur. Aset taman sebagai sumber daya alam tercermin melalui keberadaan vegetasi di dalam taman yang memberikan manfaat secara ekologis bagi masyarakat perkotaan. Aspek sumber daya manusia pada aset taman terkait dengan potensi para pemangku kepentingan yang terlibat dalam pengelolaan taman seperti pemerintah daerah, swasta, dan masyarakat. Selanjutnya, aspek infrastruktur pada aset taman ditunjukkan oleh unsur buatan seperti sarana bermain, sarana olahraga, tempat duduk, penerangan, tempat sampah, dan elemen penghias yang memberikan banyak manfaat bagi para pengunjung taman. Keinginan masyarakat yang tinggal di Perumahan Villa Bogor Indah sejalan dengan program Pemerintah Kota Bogor dalam mewujudkan visi dan misinya. Untuk mewujudkan taman lingkungan di permukiman ini maka dilakukan kegiatan yang bertujuan untuk membuat desain dan melakukan pembangunan taman lingkungan berbasis partisipasi masyarakat di Perumahan Villa Bogor Indah.

\section{METODOLOGI}

Kegiatan ini dilakukan di salah satu taman lingkungan yang ada di perumahan. Dilakukan di lokasi ruang terbuka hijau, Perumahan Villa Bogor Indah, Kecamatan Bogor Utara, Kota Bogor. Kegiatan ini dilakukan pada bulan September sampai bulan Desember 2018.

Kegiatan desain taman lingkungan di permukiman ini merupakan partisipasi aktif dari Bidang Pertamanan, PJU, dan Dekorasi Kota, Dinas Perumahan dan Permukiman, Pemerintah Kota Bogor, Program Studi Arsitektur, Fakultas Teknik dan Ilmu Komputer, Universitas Indraprasta PGRI, Jakarta, dan masyarakat penghuni Perumahan Villa Bogor Indah. Metode yang digunakan adalah metode deskriptif kualitatif dengan pendekatan desain berbasis komunitas (community based design) yang memadukan metode Hester (1990), Booth (1983), dan Motloch (2001). Tahapan di dalam penelitian sebagai berikut: 1) melakukan diskusi 
penetapan lokasi dengan Bidang Pertamanan, PJU dan Dekorasi Kota, Pemerintah Kota Bogor; 2) Peninjauan lokasi perencanaan dan desain dengan Bidang Pertamanan, PJU dan Dekorasi Kota, Pemerintah Kota Bogor; 3) inventarisasi kondisi, luas dan letak lokasi; 4) identifikasi biofisik lokasi; 5) diskusi dengan instansi pemerintah dan masyarakat untuk mendapatkan persepsi dan keinginannya; 6) identifikasi pola prilaku penggunaan lokasi; 7) analisis tapak; 8) diskusi pola ruang, aktivitas dan fasilitas yang diinginkan oleh masyarakat dan persepsi Bidang Pertamanan, PJU, dan Dekorasi Kota, Pemerintah Kota Bogor; 9) konsep pengembangan tapak; 10) rencana tapak; 11) desain pengembangan tapak; dan 12) pembangunan taman lingkungan bersama masyarakat.

Kegiatan diawali dengan melakukan penetapan lokasi yang akan dibangun taman di lingkungan permukiman. Bidang Pertamanan, PJU dan Dekorasi Kota mempunyai otoritas untuk menentukan lokasi berdasarkan program yang telah direncanakan untuk memenuhi jumlah luas Ruang Terbuka Hijau Kawasan Perkotaan (RTHKP) yang harus dicapai oleh Kota Bogor. Kegiatan selanjutnya adalah melalui peninjauan lokasi bersama aparat pemerintahan kecamatan dan kelurahan serta ketua RT dan RW setempat dan warganya. Saat peninjauan lokasi dilanjutkan dengan pengukuran batas lokasi, menginventarisasi kondisi biofisik dan aktivitas yang dilakukan. Hasil inventarisasi yang telah dilakukan merupakan bahan pembuatan peta invetarisasi dan informasi mengenai kondisi tapak. Kegiatan dilanjutkan dengan melakukan penjaringan persepsi dan keinginan masyarakat. Hal ini dilakukan untuk mengetahui keinginan masyarakat terhadap aktivitas dan fasilitas yang dapat disediakan dan diakomodasi pada tapak tersebut. Hasil analisis menunjukkan bahwa potensi yang terdapat dalam tapak dioptimalkan untuk mendukung aktivitas dan fasilitas yang diinginkan oleh warga setempat. Di dalam tapak juga ditemui berbagai kendala, misal area yang dijadikan tempat pembuangan sampah oleh warga (Gambar 2).
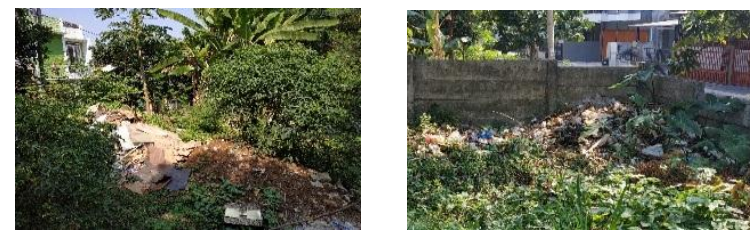

Gambar 2. Kendala Tapak
Kondisi merupakan pertimbangan untuk segera dapat diakomodasi dalam perencanaan yang dihasilkan. Kegiatan analisis tapak dilakukan bersama warga setempat. Kegiatan selanjutnya adalah melakukan perencanaan dan desain. Kegiatan perencanaan dan desain tapak mengalami revisi atau perbaikan sesuai dengan yang diinginkan warga dan sesuai dengan biaya yang akan dikeluarkan oleh Bidang Pertamanan, Pemerintah Kota Bogor. Kegiatan ini diakhiri dengan melakukan pembangunan taman lingkungan di permukiman tersebut.

\section{HASIL DAN PEMBAHASAN Kondisi Umum}

Lokasi kegiatan berada di taman lingkungan Perumahan Villa Bogor Indah, Kecamatan Bogor Utara, Kota Bogor. Jumlah penduduk di Kecamatan Bogor Utara untuk lakilaki 97.765 jiwa dan perempuan 95.047 jiwa (BPS, 2017). Luas lokasi 1680,749 $\mathrm{m} 2$, dimana didominasi oleh perkerasan lapangan dan ruang untuk pohon-pohon.Kondisi lokasi kegiatan dapat dilihat pada Gambar 3. Sebelah selatan dan timur adalah hunian perumahan Villa Bogor Indah, sedangkan sebelah utara adalah batas lokasi serta sebelah barat adalah lahan kosong.

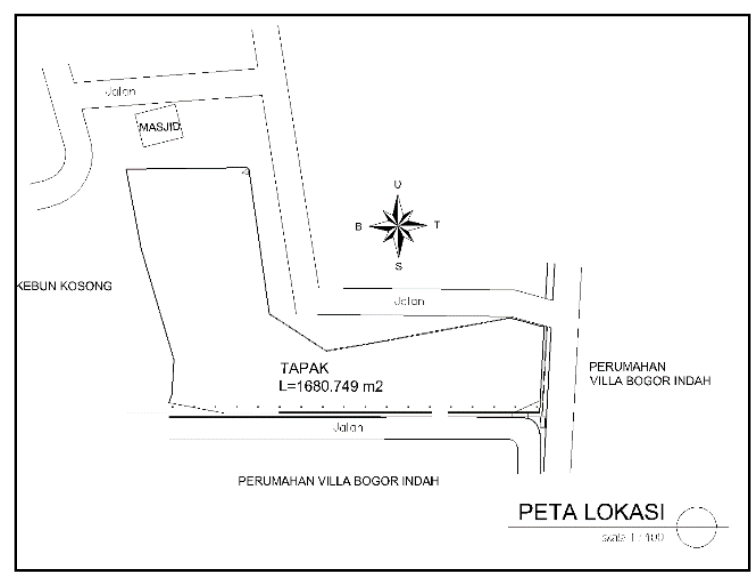

Gambar 3. Lokasi kegiatan

Taman lingkungan ini berada di pusat Perumahan Villa Bogor Indah. Posisi lokasi yang berada di sentra ini mendorong penghuni sering untuk melakukan aktivitas bersama-sama. Aktivitas yang sering dilakukan oleh warga penghuni berkaitan dengan taman lingkungan ini adalah bercocok tanam tanaman langka dan tanaman obat dan sayuran. Kondisi saat ini, lahan ini terbengkalai tanpa kegiatan pemeliharaan yang rutin. Keberadaan RTH memberikan 
manfaat untuk aktivitas fisik, interaksi sosial dan manfaat psikologis (de Bell, Graham, Jarvis, dan White, 2017), memberikan manfaat kesehatan (Coppel dan Wustemann, 2017), dan kenyamanan untuk manusia (Ak, dan Ozdede, 2016).

Lokasi kegiatan terletak pada kemiringan lahan yang beragam mulai datar, landai, hingga agak terjal (Gambar 4). Terdapat perbedaan ketinggian yang cukup tinggi antara jalan dan lokasi di sebelah timur dan utara, sedangkan tidak terdapat perbedaan ketinggian yang cukup signikan dengan kemiringan lahan yang cukup landai. Lokasi kegiatan ke arah selatan menurun, sebagai alur untuk membuang limpasan air. Kondisi kemiringan lahan memudahkan untuk membuat hutan kota dan urban farming.

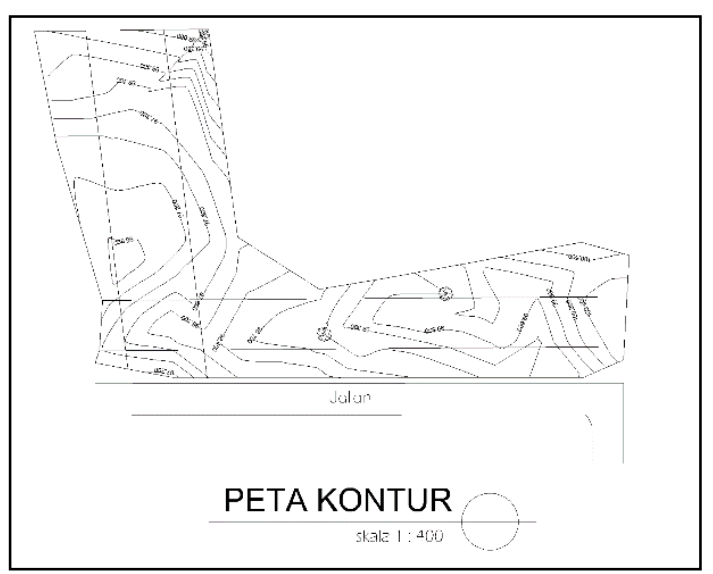

Gambar 4. Kondisi ketinggian dan kemiringan permukaan lahan

Suhu udara di Kota Bogor berkisar antara $25^{\circ} \mathrm{C}$ sampai $40^{\circ} \mathrm{C}$. Curah hujan cukup tinggi, yaitu rata-rata antara $5.000 \mathrm{~mm}$ sampai dengan $7.500 \mathrm{~mm}$ per tahun. Musim hujan biasanya berkisar antara bulan September sampai Februari, sedangkan kemarau biasanya dari bulan Maret sampai dengan Agustus. Jumlah hari hujan ratarata lebih panjang dari 6 bulan dalam setahunnya dan kecepatan angin berkisar antara 7-12 mil/jam, sedangkan kelembaban (RH) maksimum antara 94-98\%.

Drainase berada di sisi luar sebelah selatan. Permukaan lokasi lebih tinggi dibandingkan dengan drainase sehingga memudahkan air mengalir ke drainase. Sistem drainasi yang ada di dalam tapak adalah sistem drainase terbuka. Sistem ini memudahkan untuk melakukan pemeliharaan aliran air dan kondisi drainase itu sendiri.
Di lokasi tidak terdapat jaringan utilitas baik pipa air, listrik maupun telepon. Sebagian besar penerangan taman dialirkan melalui rumah masyarakat yang ada di dekatnya. Jaringan listrik terdapat di luar lokasi, yang biasanya digunakan untuk lampu penerangan jalan dan rumah. Sama seperti halnya jaringan air bersih dan telepon. Masyarakat menginginkan adanya lampu penerangan di taman lingkungan ini dan sumur sebagai sumber air untuk memelihara tanaman.

\section{Analisis Tapak}

Beberapa permasalahan dan potensi tapak ditemui, baik saat melakukan inventarisasi tapak maupun saat melakukan public hearing bersama stakerholders dan masyarakat penghuni Perumahan Villa Bogor Indah, Kota Bogor (Gambar 4). Permasalahan utama yang sangat terlihat adalah kurang terawatnya lokasi yang akan diperuntukkan sebagai arboretum dan urban farming. Permasalahan lain yang terlihat adalah tidak terawatnya pohon-pohon dan rumput yang ada. Di lain hal terdapat potensi tapak yang dapat digunakan untuk aktivitas urban farming dan hutan kota ruang untuk tanaman baik rumput, semak, perdu maupun pohon baik tanaman obat, tanaman buah-buahan dan tanaman kehutanan (Gambar 5).

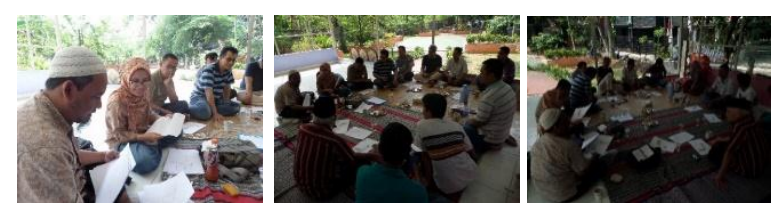

Gambar 5. Suasana public hearing bersama masyarakat dan stakeholders

Permasalahan yang terjadi di lokasi memerlukan tindakan untuk mengatasinya, Hasil public hearing bersama masyarakat menginginkan tindakan untuk memperbaiki kondisi lapangan dan memfungsikannya menjadi lokasi urban farming, arboretum dan tempat parkir serta aktivitas rekreasi masyarakat. Selain itu juga terdapat fasilitas jalur sirkulasi pejalan kaki, penerangan, menempatkan fasilitas tempat sampah, memangkas tajuk pohon yang lebih baik, dan menanam tanaman yang mudah dalam perawatan dan ditanam secara massal gazebo dan sumur (Gambar 6). Penghuni permukiman menginginkan taman lingkungan dapat berfungsi sebagai sarana urban farming $55 \%$, sebagai arboretum $40 \%$ dan sebagai sarana rekreasi pasif $5 \%$ (Gambar 7). 


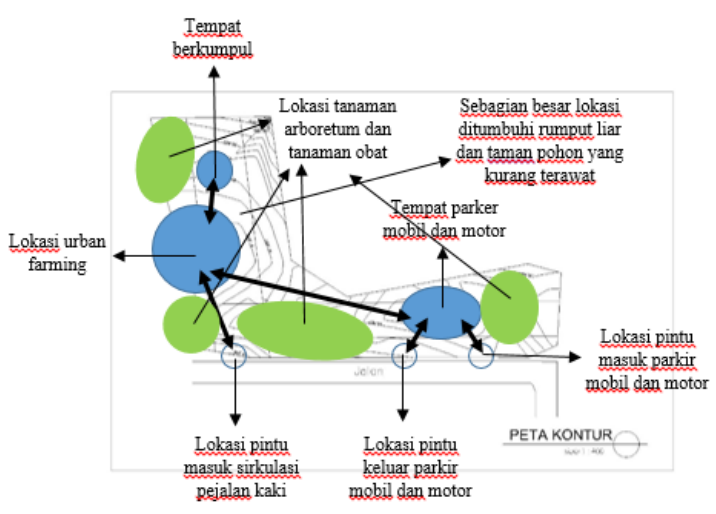

Gambar 6. Analisis tapak dan keinginan pengguna

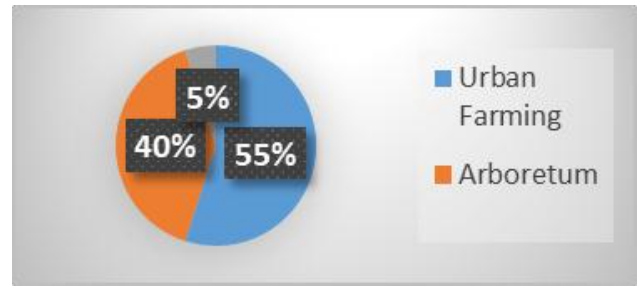

Gambar 7. Fungsi taman lingkungan yang diinginkan oleh penghuni permukiman

\section{Konsep Pengembangan Tapak}

Beberapa fungsi yang dapat dikembangkan di taman lingkungan Perumahan Villa Bogor Indah, yakni : 1) urban farming; 2) arboretum; 3) rekreasi pasif; dan 4) parkir. Hubungan antar fungsi dapat dilihat pada Gambar 8. Aktivitas-aktivitas yang dapat dilakukan dalam Taman Lingkungan Permukiman Graha Indah dapat dilihat pada Tabel 1. Diagram keterhubungan fungsi dalam tapak taman lingkungan dapat dilihat pada Gambar 9.

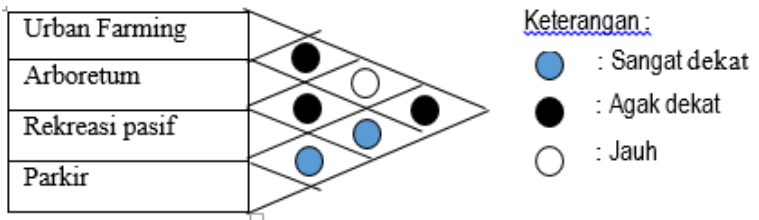

Gambar 8. Hubungan fungsi ruang

Tabel 1. Aktivitas-aktivitas yang dikembangkan di Taman Lingkungan Perumahan Villa Bogor Indah

\begin{tabular}{llll}
\hline No & $\begin{array}{l}\text { Fungsi- } \\
\text { Fungsi }\end{array}$ & \multicolumn{2}{l}{ Aktivitas-Aktivitas } \\
\hline 1. & Urban & a. & Kebun tanaman \\
& Farming & & sayur \\
& & b. Kebun tanaman obat \\
& & c. Kebun tanaman \\
& & & bumbu dapur
\end{tabular}

d. Jalan di sekitar kebun

\begin{tabular}{lll}
\hline 2. Hutan Kota & a. & Bertanam tanaman \\
& hutan kota untuk \\
& tanaman buah \\
& b. Bertanam tanaman \\
& hutan kota untuk \\
& tanaman obat \\
& c. Bertanam tanaman \\
& hutan kota untuk \\
& \\
& tanaman langka \\
& d. Bertanam tanaman \\
& & rumput \\
\hline 3. & Rekreasi pasif & a. Duduk-duduk \\
& b. Berkumpul \\
& c. Mengobrol \\
& d. Membaca \\
& e. Jalan-jalan \\
\hline 4. Parkir & a. Parkir kendaraan \\
& mobil \\
& b. Parkir kendaraan \\
& & sepeda motor \\
\hline
\end{tabular}

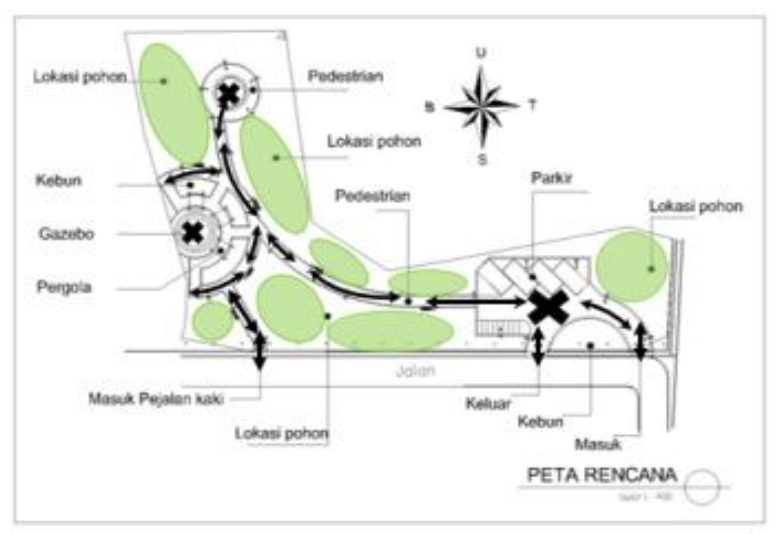

Gambar 9. Diagram keterhubungan fungsi dalam tapak

\section{Rencana Tapak}

"Taman lingkungan sebagai lahan pertanian perkotaan dan hutan kota yang nyaman, aman dan produktif " merupakan konsep dasar dalam pengembangan tapak Taman Lingkungan Perumahan Villa Bogor Indah, Kota Bogor. Tapak taman lingkungan ini direncanakan berbasis persepsi, keinginan dan prilaku masyarakat penghuni lingkungan tersebut. Hester (1990) dan Weber, Boley, Palardy, dan Gaither (2017) mengemukakan dalam merencanakan sebuah tapak yang berkaitan dengan pemenuhan kebutuhan pengguna (manusia), sebaiknya diketahui persepsi, keinginan dan prilaku dalam 
penggunaan tapak tersebut. Keberadaan masyarakat sebagai pengguna tapak merupakan pemeran utama dalam keberhasilan desain suatu taman lingkungan. Pola dan fungsi tapak yang dikembangkan merupakan hasil menerjemahkan persepsi, keinginan, dan prilaku yang terjadi.

Ramah lingkungan yang merupakan tujuan yang ingin dicapai dalam konsep ini adalah : 1) terbukanya pemanfaatan taman lingkungan tersebut ini untuk seluruh masyarakat penghuni, 2)elemen yang digunakan memadukan antara elemen fisik dan elemen biologi yang tidak mengakibatkan kecelakaan dan semaksimal mungkin dapat memasukkan air limpasan ke dalam tanah dan elemen hijauan baik tanaman pohon, tanaman semak, tanaman perdu, tanaman penutup tanah, dan tanaman rumput. Estetika yang dimaksud adalah estetika ruang dan estetika elemen.Estetika ruang yang dimaksud berkaitan dengan kenyamanan visual, kenyamanan thermal, dan kenyamanan gerak. Estetika elemen yang dimaksud adanya keindahan elemen-elemen lanskap yang dihadirkan di dalam taman lingkungan tersebut.

Ruang yang direncanakan dalam taman lingkungan yakni : 1) ruang urban farming; 2) ruang arboretum; 3) ruang rekreasi pasif; 4) ruang parkir. Konsep rencana ruang dapat dilihat pada Gambar 10. Ruang urban farming direncanakan untuk aktivitas menanam tanaman kebun sayuran, tanaman obat-obatan dan tanaman bumbu dapur. Ruang hutan kota direncanakan untuk aktivitas penanaman tanaman obat-obatan, tanaman langka dan tanaman buah-buahan serta tanaman rumput. Ruang rekreasi pasif direncanakan untuk aktivitas pejalan kaki, duduk-duduk di tepi pedestrian, duduk-duduk di gazebo, dan duduk-duduk di sekitar lokasi kebun sayuran. Tempat rekreasi, kawasan perkantoran, kawasan permukiman, dan kegiatan lainya menuntut tersedianya tempat parkir (Hakim, 2012). Ruang parkir direncanakan untuk aktivitas parkir mobil, parkir kendaraan bermotor, dan parkir sepeda. Tanaman pohon yang ada di lokasi sebagai tanaman eksisting tetap dipertahakan.Keberadaan tajuk pohon dapat mengurangi radiasi matahari, menurunkan suhu setempat, dan dapat menyimpan energi untuk kesehatan lingkungan (de Abreu-Harbich, Labaki, Matzarakis, 2015). Tanaman pohon yang ditanam adalah nam-nam, asam jawa, melinjo, kelapa hibrida, kelapa hijau, rambutan, jambu air, jambu bol, sawo duren, sawo kecik, sirsak, srikaya, cempaka, dan mahoni
(Gambar 11). Tanaman sayuran dan tanaman obat yang rencana ditanam adalah tanaman bumbu dapur dan tanaman sayuran yang biasa dibeli oleh ibu-ibu rumah tangga seperti kangkung, bayam, caisim.Tanaman rumput yang digunakan adalah rumput gajah mini. Keberadaan tanaman terutama pohon dapat menurunkan suhu permukiman (lingkungan ketetanggaan) sehingga perlu direncanakan dan didesain dalam skala lingkungan ketetanggaan (Wu, dan Chen, 2017; Lin, Lau, Qin, dan Gou, 2017). Kebutuhan parkir tamu yang membawa kendaraan bermotor diperlukan sehingga memerlukan ruang di taman lingkungan. Direncanakan parkir dapat menampung 4 mobil dan 8 motor.

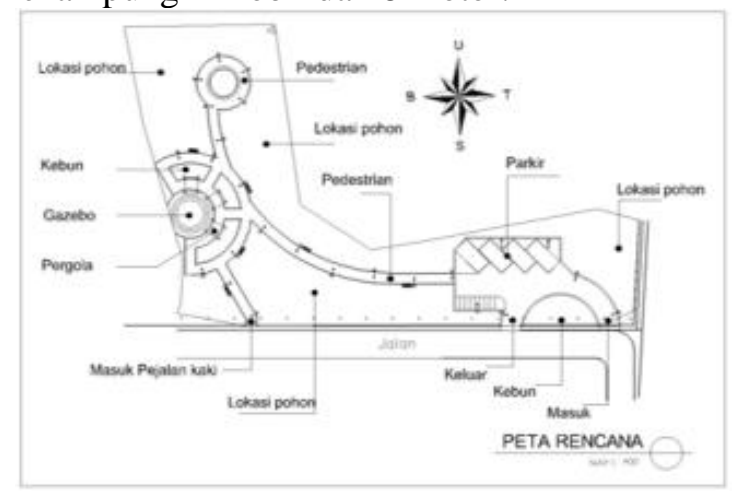

Gambar 10. Rencana tapak taman lingkungan Perumahan Villa Bogor Indah

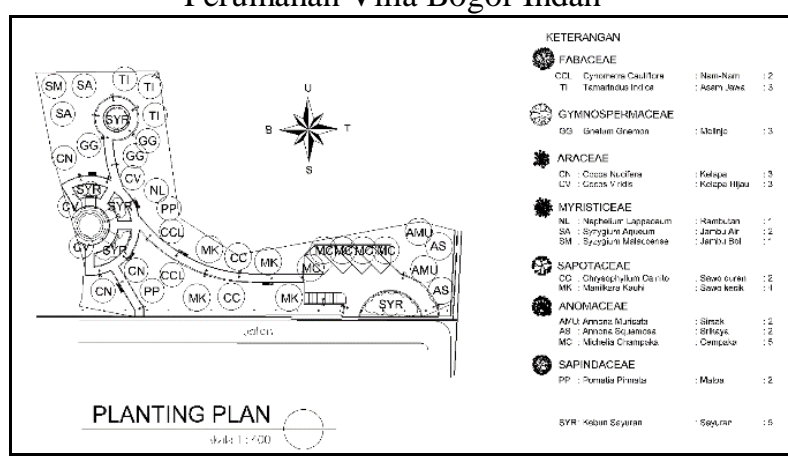

Gambar 11. Rencana tanaman taman lingkngan Perumahan Villa Bogor Indah

Fasilitas-fasilitas direncanakan tersebar di beberapa ruang. Fasilitas tersebut adalah : 1) gazebo; 2) saluran drainase; 3) pergola; 4) tempat sampah; 5) bangku taman; 6) grassblock untuk pejalan kaki dan area parkir; 7) lampu taman; 8) dinding penahan akar pohon (Gambar 12). Fasilitas-fasilitas ini digunakan untuk memberikan pelayanan kepada pengguna dalam beraktivitas di taman lingkungan ini. Gambar teknis ini mengacu kepada pedoman yang dibuat oleh Harris dan Dines (1998). 


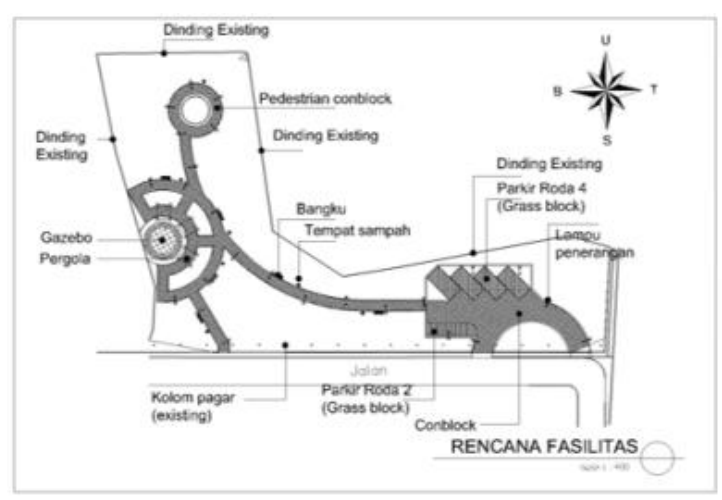

Gambar 12. Rencana fasilitas taman lingkngan Perumahan Villa Bogor Indah

Gazebo merupakan salah satu fasilitas yang disediakan di kawasan ini, gazebo ini difungsikan sebagai tempak duduk-duduk dan bersantai warga sekitar untuk melihat pemandangan yang ada disekitarnya (Gambar 13). Gazebo ini berbentuk persegi enam, memiliki atap serta dinding yang terbuka. Struktur utama dari gazebo ini adalah menggunakan pipa galvanis (GIP) dengan diameter $100 \mathrm{~mm}$ dilengkapi dengan baut dan las untuk memperkuat struktur. Struktur atap menggunakan penutup atap seng metal agar tahan lama, serta menggunakan gording yang terbuat dari kayu untuk penahannya. Didalamnya terdapat bangku untuk tempat duduk-duduk santai yang terbuat dari beton cor.

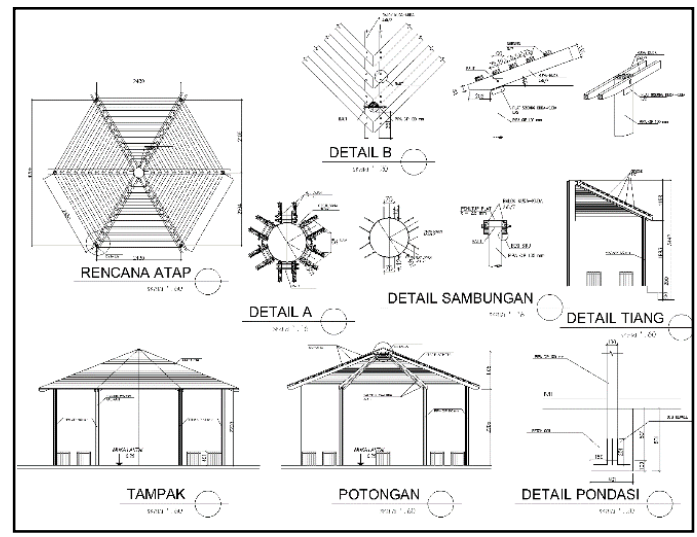

Gambar 13. Rencana gazebo taman lingkungan Perumahan Villa Bogor Indah

Untuk menambah estetika dan peneduh bagi pejalan kaki, maka dibuatlah fasilitas berupa pergola (Gambar 14). Pergola ini diletakkan di area pedestrian, yang berfungsi untuk memberi keteduhan bagi pejalan kaki (selain untuk estetika). Pergola umumnya dijumpai pada taman-taman kota, outdoor cafe, jalur pedestrian, pintu-pintu masuk suatu area dan bangunan (rumah, kantor, area rekreasi) serta berbagai yang perlu peneduh lainnya (Adriani dan Nurisyah, 2015). Pergola ini dibuat menggunakan material kayu, dengan struktur pondasi menggunakan beton cor dengan perkuatan berupa baut dan plat baja. Untuk menambah nilai estetika dari pergola ini maka ditambahkan hiasan berupa profil kayu yang dibuat seperti anyaman.

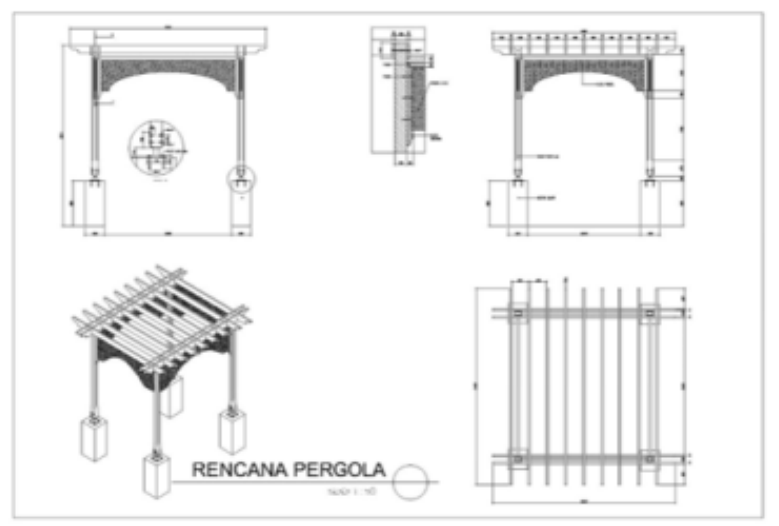

Gambar 14. Rencana pergola taman lingkungan Perumahan Villa Bogor Indah

Agar kondisi taman tersebut tetap terjaga dan bersih maka ditambahkan fasilitas berupa tempat sampah dibeberapa sudut taman, terletak di pinggir sekitar pedestrian, dengan harapan para pengunjung dapat membuang sampah di tempat sampah yang telah disediakan. Tempat sampah yang digunakan merupakan tempat sampah yang sudah didesain sesuai desain gambar (Gambar 15), menggunkan penutup agar tidak bau dan kotor, terbuat dari besi serta terdapat kaki penyangga yang juga terbuat dari besi (GIP). Tempat sampah dan kaki penyangga dibuat terpisah agar dapat diambil dan dibersihkan setiap saat.

Untuk fasilitas bagi pejalan kaki maka dibuatlah jalur khusus, jalur ini merupakan pedestrian dibuat menggunakan material conblok serta kanstin yang dilengkapi dengan pipa pembuangan air hujan di kiri dan kanan. Lebar pedestrian yaitu $1.5 \mathrm{~m}$ 


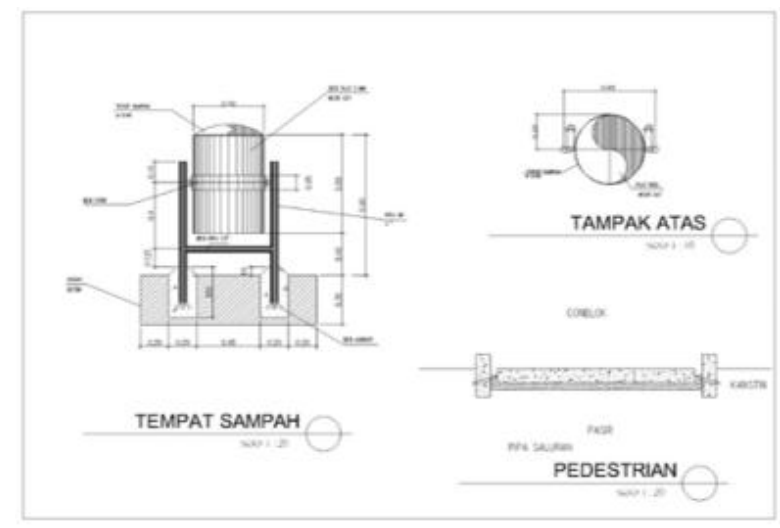

Gambar 15. Rencana tempat sampah taman lingkungan Perumahan Villa Bogor Indah

Tempat duduk disediakan juga di dalam taman ini, berfungsi sebagai tempat beristirahat bagi para pengunjung yang berjalan kaki, sambil menikmati pemandangan disekitarnya. Tempat duduk juga diletakkan tersebar di sepanjang pedestrian dengan jarak sekitar $50 \mathrm{~m}$ sd $75 \mathrm{~m}$. Bangku taman dibuat mengunakan material bata expose untuk kaki bangku dengan struktur pondasi adalah beton cor. Untuk dudukan bangku dibuat dari material besi (canal C) yang diperkuat dengan baut agar lebih tahan lama (Gambar 16).

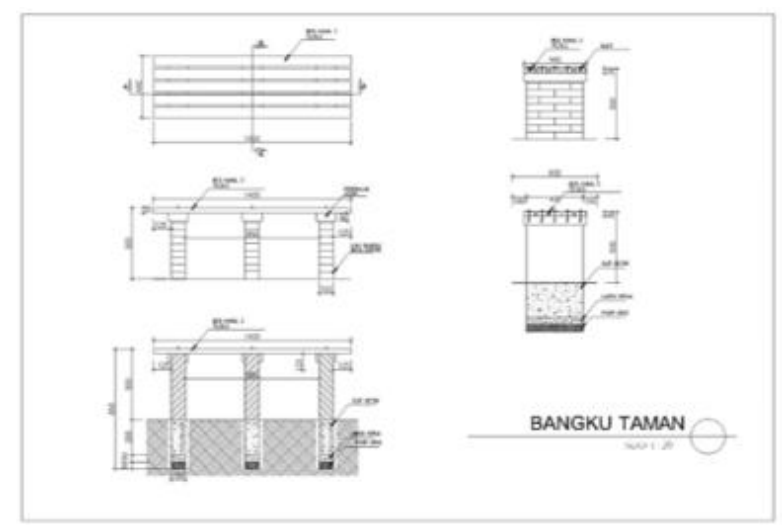

Gambar 16. Rencana bangku taman taman lingkungan Perumahan Villa Bogor Indah

Untuk penerangan di malam hari, didalam taman juga diberikan fasilitas berupa lampu taman. Lampu ini akan memberikan nilai tambah estetika terhadap taman tersebut. Lampu taman ini tersebar di beberapa sudut taman, serta terpasang di sepanjang jalur pedestrian. Lampu taman taman mempunyai ketinggian sekitar 4.5 $\mathrm{m}$, dengan struktur utama adalah pipa besi dengan penambahan besi profil untuk menambah nilai estetika (Gambar 17).

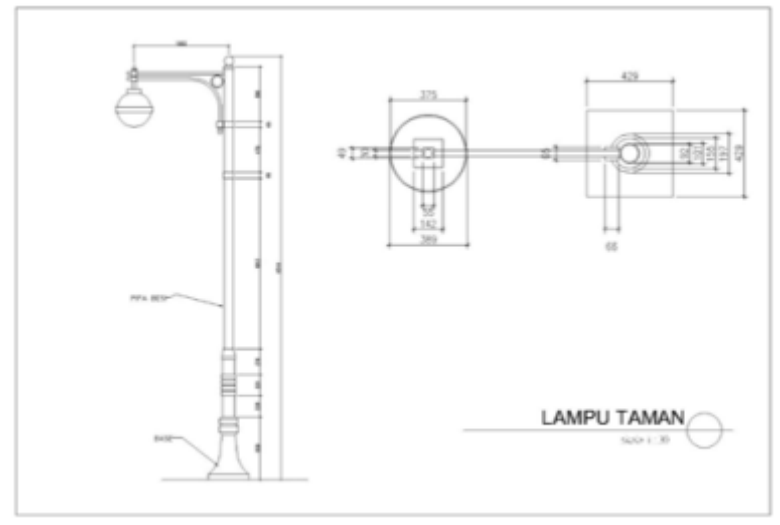

Gambar 17. Rencana lampu taman taman lingkungan Perumahan Villa Bogor Indah

\section{Pembangunan Taman Lingkungan Perumahan Villa Bogor Indah}

Hasil desain teknis taman lingkungan Perumahan Villa Bogor Indah yang telah disepakati bersama masyarakat dan Bidang Pertamanan, PJU, Dekorasi Kota, Dinas Perumahan dan Permukiman, Pemerintah Kota Bogor dibangun bersama-sama dengan masyarakat melalui pembiayaan yang diberikan oleh Pemerintah Kota Bogor. Tahapan pembangunan yang dilakukan adalah sebagai berikut : 1) pembersihan lahan; 2) pengukuran tapak; 3) pembuatan bowplank; 4) pekerjaan pembangunan lahan parkir; 5) pekerjaan pembangunan jalan setapak; 6) perbaikan pagar taman lingkungan, 7) pekerjaan pembangunan gazebo; 8) pekerjaan penanaman tanaman koleksi; 9) pekerjaan penanaman tanaman rumput; 10) pekerjaan penanaman tanaman sayuran, bumbu dapur, dan obat-obatan. Masyarakat penghuni Perumahan Villa Bogor Indah mempunyai tugas untuk mengawasi dan melakukan penanaman tanaman baik tanaman pohon, sayuran, bumbu dapur, dan obatobatan.Pekerjaan pembanguna parkir, pembangunan jalan setapak, pembangunan pagar, dan pembangunan gazebo dikerjakan oleh pekerja harian dan dibantu oleh masyarakat.Proses pembangunan dapat dilihat pada Gambar 18, 19, $20,21,22,23,24$.
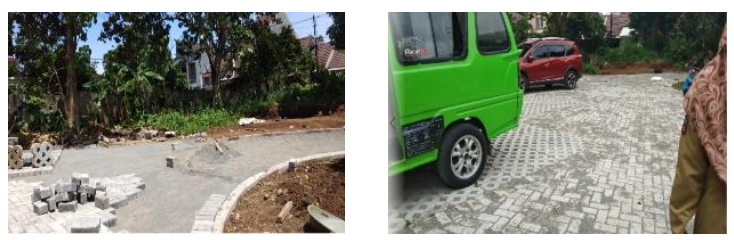

Gambar 18. Pembangunan lahan parkir 

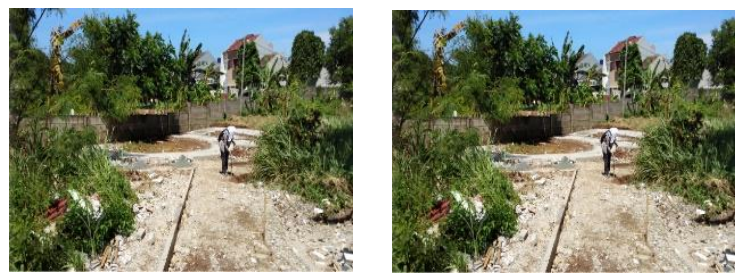

Gambar 19. Pembangunan jalan setapak

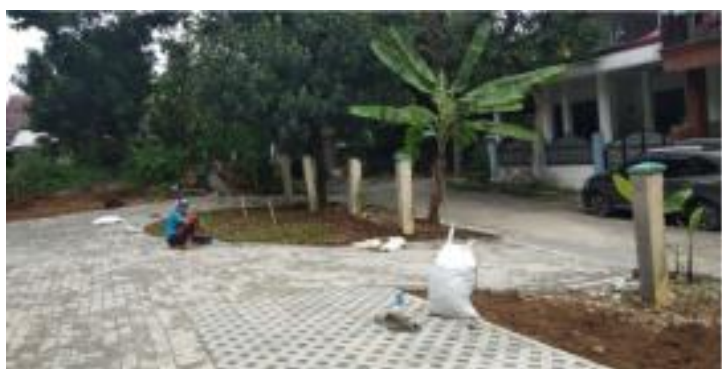

Gambar 20. Perbaikan pagar taman lingkungan

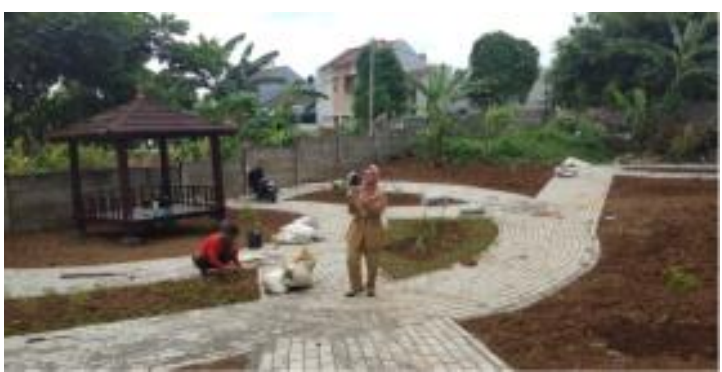

Gambar 21. Pembangunan gazebo

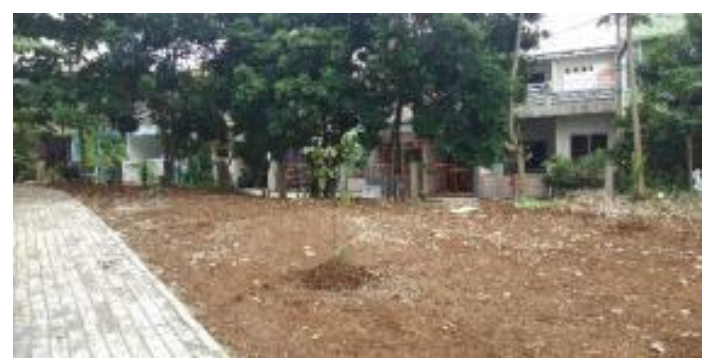

Gambar 22. Penanaman tanaman koleksi

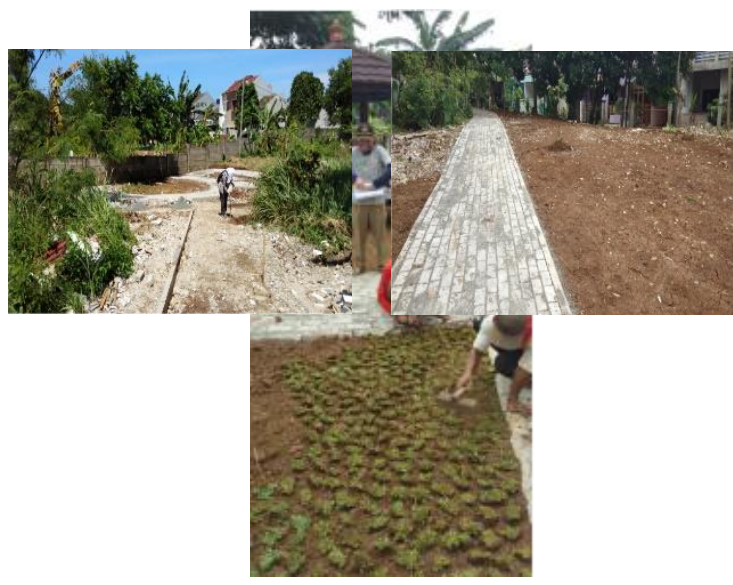

Gambar 23. Pekerjaan Penanaman Rumput

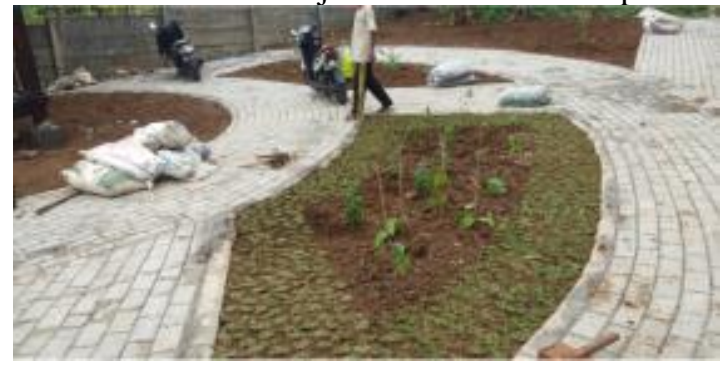

Gambar 24. Pekerjaan penanaman tanaman sayuran, bumbu dapur, dan tanaman obat-obatan

\section{PENUTUP \\ Simpulan}

Pembangunan taman lingkungan sebagai bagian dari upaya memenuhi luas dari Ruang Terbuka Hijau Kawasan Perkotaan (RTHKP) merupakan upaya bersama dari masyarakat, pemerintah daerah, pihak swasta, dan perguruan tinggi. Kebersamaan dalam proses pembangunan memudahkan mewujudkan taman lingkungan yang nyata dapat digunakan masyarakat. Pembangunan taman lingkungan Perumahan Villa Bogor Indah mencapai keberhasilan yang baik didasarkan pada pembangunan taman lingkungan berbasis aktivitas komunitas masyarakat. Kegiatan ini dapat mengakomodasikan seluruh stakeholders secara bersama-sama dan terpadu. Program Studi Arsitektur, Fakultas Teknik dan Ilmu Komputer, Universitas Indraprasta memiliki kemampuan akademis dalam bidang desain teknis dan pengawasan teknis pembangunan, sehingga arah pembangunan taman lingkungan ini dapat terwujud dan mudah untuk dilakukan.

\section{Saran}

Kegiatan yang mengakomodasi stakerholders secara bersama untuk mewujudkan 
suatu pembangunan berbasis aktivitas komunitas selayaknya dapat dilanjutkan pada lokasi tamantaman lingkungan lainnya. Arah ke depan kegiatan-kegiatan pembangunan taman-taman lainnya dapat lebih melibatkan stakeholders yang lebih luas. Keterbatasan pendanaan yang dimiliki oleh masyarakat dan pemerintah kota bukanlah halangan untuk mewujudkan taman lingkungan lainnya. Peran pihak swasta harus dilibatkan sebagai bagian dari kepedulian terhadap pembangunan RTHKP Kota Bogor.

\section{DAFTAR PUSTAKA}

Adriani, H dan Nurisyah, S. (2015). Tanaman Memanjat Untuk Pergola. Jakarta: Ikatan Arsitek Lansekap Indonesia.

Akbari, H., Davis, S., Dorsano, S., Huang, J., \& Winnet, S. (1992). Cooling our Communities, A Guidebook on Tree Planting and Light-Coloured Surfacing Washington: Lawrence Berkeley Laboratory.

Ak, M.K dan Ozdede, S. (2016). Urban Landscape Design and Planning Related To Wind Effects. Oxidation Communications 39 (1-II): 699-710.

[APA] American Planning Association. (2007). Neighborhood Park. https://www.planning.org/search/?keyword $=$ Neighborhood+park. Diunduh tanggal 25 Juni 2017.

Booth, N.K. (1983). Basic Element of Landscape Architectural Design. Illinois (US): Waveland Press, Inc.

[BPS] Badan Pusat Statistik. (2017). Kota Bogor Dalam Angka 2017. Bogor (ID): Badan Pusat Statistik Kota Bogor.

Coppel, G dan Wustemann, H. (2017). The impact of urban green space on health in Berlin, Germany: Empirical findings and implications for urban planning. $J$. Landscape and Urban Planning 167: 410418. http://dx.doi.org/ 10.1016/j.landurbplan.2017.06.015. de Abreu-Harbich, L.V, Labaki, L.C, Matzarakis, A. (2015). Effect of tree planting design and tree species on human thermal comfort in the tropics. J. Landscape and Urban Planning 138: 99-109. http://dx.doi.org/10.1016/j.landurbplan.201 5.02.008.

de Bell, S, Graham, H, Jarvis, S, dan White, P. (2017). The importance of nature in mediating social and psychological benefits associated with visits to freshwater blue space. J. Landscape and Urban Planning 167: 118-127. http://dx.doi.org/ 10.1016/j.landurbplan.2017.06.003.

DOE. (1993). Tomorrow's Energy Today for Cities and Countries: Cooling Our Cities U.S. Department of Energy, 1-6.

Hakim, R. (2012). Komponen Perancangan Arsitektur Lansekap. Jakarta: PT. Bumi Aksara

Harris, C.W dan Dines, N.T. (1998). Time Saver Standard for Landscape Architecture. New York (US): McGraw-Hill Publ. Company.

Hester, R.T.Jr. (1990). Community Design Primer. Mendocini, Calif: Ridge Time Press.

Kwon, M, Lee, C, dan Xiao, Y. (2017). Exploring the role of neighborhood walkability on community currency activities: A case study of the crooked river alliance of TimeBanks. J. Landscape and Urban Planning 167: 302-314. http://dx.doi.org/ 10.1016/ j.landurbplan.2017.07.008.

Lin, P, Lau, S.S.Y, Qin, H, dan Gou, Z. (2017). Effects of urban planning indicators on urban heat island: a case study of pocket parks in high-rise high-density environment. J. Landscape and Urban Planning 168: 48-60. http://dx.doi.org/ 10.1016/ j.landurbplan.2017.09. 024. 
Motloch, J.I. (2001). Introduction to Landscape Design. Canada (US): John Wiley \& Sons Inc.

[Permen PU] Peraturan Menteri Pekerjaan Umum. (2008). Peraturan Menteri Pekerjaan Umum Nomor : 05/PRT/M/2006 tentang Pedoman Penyediaan dan Pemanfaatan Ruang Terbuka Hijau Di Kawasan Perkotaan. Direktorat Jenderal Penataan Ruang, Departemen Pekerjaan Umum, Republik Indonesia

Puspitarini, F.D, Nurhayati, dan Arifin, H.S (2017). Landscape Managemen of Public Open Space ini Bogor Heritage City. Di dalam : Kaswanto RL, Mugnisjah WQ, Arifin HS, Ismail NA, dan Kobayashi T, editor. $2^{\text {nd }}$ International Symposium for Sustainable Landscape Development; 2016 November 9-10; Bogor, Indonesia. Bogor (ID): IOP Publ., hlm 012020.

Sidle, R.C, Gallina, J, dan Gomi, T. (2017). The continuum of chronic to episodic natural hazards: Implications and strategies for community and landscape planning. $J$. Landscape and Urban Planning 167: 189 197. http:// dx.doi.org/10.1016/j.landurbplan. 2017.05.017.

Siregar, D.D. (2004). Manajemen aset: strategi penataan konsep pembangunan berkelanjutan secara nasional dalam konteks kepala daerah sebagai CEO's pada era globalisasi \& otonomi daerah. Jakarta: PT Gramedia Pustaka Utama. Di dalam : Prayogi SF, Isdianto B, dan Ihsan M. Eksperimen teori human centered design pada elemen fisik taman kresna kota bandung. Jurnal Sosioteknologi Volume 13, Nomor 3, Desember 2014.

Weber, S, Boley, B.B, Palardy, N, Gaither, C.J. (2017). The impact of urban greenways on residential concerns: Findings from the Atlanta BeltLine Trail. J. Landscape and Urban Planning 167: 147-156. http://dx.doi.org/ 10.1016/j.landurbplan. 2017.06. 009.

Wu, Z dan Chen, L. (2017). Optimizing the spatial arrangement of trees in residential neighborhoods for better cooling effects: Integrating modeling with in-situ measurements. J. Landscape and Urban Planning 167: 463-472. http://dx.doi.org/ 10.1016/ j.landurbplan.2017.07.015. 